\title{
EMPRESARIALES
}

\section{Inclusión financiera desde la perspectiva de género: un análisis del empoderamiento económico del programa de créditos "Mujer Emprendedora" de inclusión financiera para micro-emprendimientos del Crédito Agrícola de Habilitación otorgado a mujeres rurales de los distritos de J. A. Saldívar, Guarambaré e Itauguá. Periodo 2012-2016}

\author{
Ángel Rodrigo Aguilar Orrego, Marcela Fernanda Achinelli Báez¹
}

\section{Resumen}

Introducción: El rol de la mujer en la sociedad ha sido protagónico, pero no reconocido. La inclusión de la perspectiva de la mujer como agente activo en el diseño de las políticas públicas muestra signos positivos de participación, pero insuficientes a la hora de atenuar los rezagos sociales de desigualdad y discriminación. Las mujeres localizadas en áreas rurales realizan las actividades laborales y productivas como ser el cultivo, la artesanía y la cría de animales tanto en grandes como pequeñas fincas, especialmente en las pequeñas fincas. Ellas desempeñan una labor fundamental en la generación de ingresos y producción de alimentos de autoconsumo. Sin embargo, la mayoría de ellas no accede a servicios básicos elementales para la vida como ser agua potable y energía eléctrica; ni siquiera logran culminar la educación escolar básica. Las mujeres agricultoras, artesanas y emprendedoras no cuentan con un respaldo financiero que les permita acceder a créditos en el sistema formal de la economía lo cual dificulta la expansión de sus actividades económicas. El Plan Nacional de Desarrollo Paraguay 2030 establece como uno de sus ejes estratégicos el crecimiento económico inclusivo, siendo una de las líneas transversales la igualdad de oportunidades para los sectores vulnerables. Si bien los esfuerzos han sido progresivos, no fueron lo necesario para encarar la desigualdad de la realidad que toca vivir a las poblaciones rurales, en especial a las mujeres.

Objetivo: Analizar el empoderamiento económico que genera el programa de créditos "Mujer Emprendedora" de inclusión financiera para microemprendimientos del Crédito Agrícola de Habilitación de las mujeres de las

\footnotetext{
1. Universidad Nacional de Asunción. Facultad de Ciencias Económicas.

Este trabajo fue presentado para la obtención del título de grado, con la tutoría de la Econ. Marcela Achinelli.

E-mail: angelror1210@gmail.com

DOI: $10.26885 /$ rcei.foro. 2018.84
} 
zonas rurales de los distritos de J. A. Saldívar, Guarambaré e Itauguá. Periodo 2012-2016.

Material y Método: La modalidad bibliográfica-documental y de campo, utilizando el método deductivo y analítico. Posteriormente se procedió a la elaboración de encuestas para el relevamiento de datos en las zonas rurales de las ciudades mencionadas. A raíz de los resultados, se propuso alternativas que fortalecerán el alcance de los programas de inclusión financiera como el diseño de la telefonía móvil y la creación de grupos de apoyo entre beneficiarias atendiendo a la rama de actividad principal y la proximidad geográfica.

Conclusión: Se resalta que los programas de créditos de inclusión financiera logran el empoderamiento económico al propiciar mayores niveles de penetración de instituciones financieras. En este aspecto la penetración financiera es más elevada en la concesión de créditos que en la apertura de cuentas de ahorro y/o cuenta corriente o la adquisición de algún activo financiero así también eleva el grado de capacitación técnica de las mujeres del programa.

Palabras clave: mujeres, créditos, empoderamiento.

\section{Referencias}

Centro de Documentación y Estudios (CDE), Comité de América Latina y el Caribe para la Defensa de los Derechos de las Mujeres (CLADEM-PARAGUAY), Coordinación de Mujeres del Paraguay (CMP), Coordinadora de los Derechos Humanos del Paraguay, \& Equipo Feminista de Comunicacion (EFC). (2015). Paraguay a 20 años de Beijing 1995. Asunción- Paraguay.

Ledgerwood, J. (2000). Microfinance Handbook: An Institutional and Financial Perspective. Washington D. C. USA: World Bank. Recuperado de https://openknowledge. worldbank.org/bitstream/handle/10986/12383/18771.pdf

Mayoux, L. (2011). Las mujeres son útiles para las microfinanzas: ¿Cómo podemos hacer que las microfinanzas sean más útiles para las mujeres? Inglaterra: Cumbre Mundial de Microcréditos. Recuperado de http:// www.globalmicrocreditsummit2011.org/userfiles/file/Workshop\%20 Papers/Spanish/L_\%20Mayoux\%20-\%20SPANISH.pdf

Programa de las Naciones Unidas Para el Desarrollo. (2015). Pobreza, Oportunidades Económicas Desiguales y Género (No. 2) (p. 72). PNUD Paraguay. Recuperado de http://www.py.undp.org/content/dam/paraguay/docs/ documento\%20de\%20trabajo\%20COMPLETO.pdf

Rodríguez-Raga, S., \& Riaño Rodríguez, F. F. (2016). Determinantes del acceso a los productos financieros en los hogares colombianos. Determinants of access to financial products among Colombian households (English), $32,14-24$. 